\title{
New Geopolymer Adsorbents for Phosphate Removal from Diluted Solutions and their Applications
}

\author{
Tatiana Samarina, Esther Takaluoma \\ Kajaani University of Applied Sciences, \\ Ketunpolku 1, PL 52, FI-87101, Kajaani, Finland \\ tatiana.samarina@kamk.fi; esther.takaluoma@kamk.fi
}

\section{Extended Abstract}

Phosphorus (P) in the form of phosphate, phosphate esters and hydroxylapathite is an essential element for all living organism. It therefore has a non-replaceable role in fertilizers. However, some of the phosphate ends up in water bodies from field run off water in crop production. Industrial processing releases phosphate to the environment due to the high cost of its recovery. To close the nutrient loop, new and innovative ways for more efficient phosphorus cycling is therefore urgently necessary. Moreover, depletion of world phosphate deposits "Phosphorus peak" and soil contamination through cadmium and uranium contained in fertilizers produced from raw phosphate rock, eutrophication of water bodies, and P emission to the air during mining and ore processing, make the search for alternative solutions of $\mathrm{P}$ recycling attractive. The wellestablished removal techniques of $\mathrm{P}$ from waste streams are performed by physico-chemical or by biological treatment methods as well as their combinations [1], [2]. Although most of such methods are effective for large-scale industrial or domestic wastewater treatment plants (> $400 \mathrm{PE}$ ), implementation of these solutions to small-scale facilities or to remote applications may not be economically or logistically feasible.

In this work, we present the development of a low-cost adsorptive media for phosphate removal. The work aims to find an effective solution for production of adsorbents having high capacity and selectivity towards phosphate ions, on the one hand, but possessing uniform properties and ease of manufacturing on the other. For this purpose, the series of adsorbent compositions employing industrial by-products were developed. Industrial solid wastes such as fly ash F, blast furnace slag, and paper mill sludge with high calcium content were chosen as raw materials to be a primary source of $\mathrm{Ca}, \mathrm{Al}$ and $\mathrm{Si}$. Geopolymerization technique with alkaline activator was used to obtain powdered and granulated forms of adsorbents[3]. Three types of geopolymer adsorbent named fly ash F (FAF-GP), blast furnace slag (BFS-GP) and fibre sludge (FSHCa-GP) were evaluated for the adsorption of phosphate in aqueous solution. XRD and XRF methods were employed to characterize physical structure and chemical composition of primary source materials and geopolymer products. To evaluate phosphate removal efficiency of geopolymers, batch and column adsorption experiments were performed.

The effect of various operating conditions, i.e. initial $\mathrm{pH}$, adsorbent dose, initial phosphate concentration, and adsorption time has been studied. The adsorption process was relatively fast for FAF-GP, equilibrium has been reached at $1.5 \mathrm{~h}$ contact time, while for BFS-GP and FSHCa-GP the maximum removal rate was achieved at $5 \mathrm{~h}$ and $24 \mathrm{~h}$, resp. The isotherms look differently for all three adsorbents that reflects the different adsorption mechanisms. Capacities at phosphate concentration of $100 \mathrm{mg} \mathrm{L}^{-1}$ are $26 \mathrm{mg} \mathrm{PO}_{4} \mathrm{~g}^{-1}$ for BFS-GP, $36 \mathrm{mg} \mathrm{PO}_{4} \mathrm{~g}^{-1}$ for FAF-GP, and $43 \mathrm{mg} \mathrm{PO}_{4} \mathrm{~g}^{-1}$ for FSHCa-GP, respectively. A removal ratio of over $98 \%$ was achieved with an adsorbent dose of $2 \mathrm{~g} \mathrm{~L}^{-1}$ for FAF-GP and FSHCa-GP, and $4 \mathrm{~g} \mathrm{~L}^{-1}$ for BFS-GP. In all cases, the ability of the geopolymers to remove phosphate ions increased with increasing of $\mathrm{pH}$ values up to 9 and then decreased until $\mathrm{pH}$ 12. Fixed-bed continuous column experiments were carried out for all geopolymers produced in granulated form to evaluate the influence of granules size, flow rate, and adsorptive layer length on operational conditions of adsorption tower. Two samples of field run-off waters were treated in bench scale application, both water samples showed removal rates of at least 95\%. Leaching test results suggest that the spent adsorbents can be safely disposed or further reused.

This study was conducted as part of the WaterPro project (number A74635 EAKR, Keski-Pohjanmaan/Kainuun Liitto).

\section{References}

[1] R. W. Scholz, A. H. Roy, F. S. Brand, D. Hellums, and A. E. Ulrich, Eds., Sustainable Phosphorus Management: A Global Transdisciplinary Roadmap. Springer: Springer Netherlands, 2014.

[2] H. Ohtake and S. Tsuneda, Phosphorus Recovery and Recycling. Springer: Springer Singapore, 2019. 
[3] T. Luukkonen, K. Veznikova, E. T. Tolonen, H. Runtti, J. Yliniemi, T. Hu, K. Kemppainen, U. Lassi, "Removal of ammonium from municipal wastewater with powdered and granulated metakaolin geopolymer," Environ. Technol., vol. 39, no. 4, pp. 414-423, 2018. 